\title{
Research and analysis of the results from the goniometer and tribotester using the diamond - derivating coating on piston ring
}

\begin{abstract}
The elements creating friction pairs are described to be very difficult in terms of determining all optimal parameters in an unambiguous manner. The nowadays research on stability of friction pairs is focused on the surface and the top layer of surface. The main goal is find new design solutions and materials, achieving a lot of kilometers to main repair in combustion engines. The biggest structural difficulties are noticeable in friction pairs where can be observed sliding and returning motion, what is connected with sealing function. A typical example of such pair is piston ring - cylinder. Engineers work on defining an additional factor that would be able to gain the reduction of tangential force by reducing the friction coefficient in elements of friction pair. Molecular structure and nature of the bonds between the molecules presented in the material, result that the free surface energy may be such a factor, because determines the tribological properties of the material, what is reflected in the stability of the units. The work carries out of an analysis after research on the goniometer in the presence of water and diododomethane that allowed to measure wetting drops on the surface, thanks to which can be calculated surface energy. Within this work will be performed study of the energy state of the surface of piston rings with a coating including a diamond powder. After analysis on the basis of the collected measurements will be developed conclusion regarding the potential relationship between the free surface energy and wearing of the material.
\end{abstract}

Key words: piston wearing, diamond coating, goniometer, free surface energy

\section{Introduction}

This article presents the research from the goniometer on the newly developed sealing piston ring for an internal combustion engine, where the novelty is an innovative derivative coating with very good anti-wear properties with higher hardness than traditional materials (10-60 GPa), high adhesion to the substrate, high mechanical, physical and chemical stability or coefficient of friction below 0.1 [3].

Friction pairs are designed from elements, where is very difficult to define in unequivocal way all optimal parameters and research on their stability is focused on the surface and the top layer of surface. The main goal is find new solutions for design and material, thereby achieving so many kilometers of mileage to main repair in the case of internal combustion engines.

Due to the big structural difficulties that are noticeable in friction pairs where we can observe sliding and returning motion that is also connected with sealing function, engineers are currently seeking an additional factor which would be able to gain the reduction of tangential force by reducing the friction coefficient in elements of friction pair during operations.

Such a factor may be the surface free energy that results from molecular structure and nature of the bonds between the molecules presented in the material. Components of surface free energy (dispersion and polar) determine the tribological properties of the material, which is reflected in the stability of the units.

The surface free energy and its components can be obtained thanks to measurement of the wetting angle performed within the goniometer and Owens-Wendt calculation method [2].

Then, the influence of surface free energy was tested on the tribotester, checking the wearing of piston samples.

\section{Research on the goniometer}

\subsection{Preparation}

One of the possibilities to calculate the free surface energy of the element is measurement of wetting angle of the wetting drop using special instrument which is goniometer. Wetting angle can be measured with the use of the standard liquid with known value of the surface free energy and its components. This angle has a big meaning for lubrication processes and tribological point of view.

The wetting angle measurement was performed using a goniometer from the German company KRUSS GmbH. According to the procedure, the free surface energy was determined using the Owens-Wendt method, which consists in measuring the surface contact angle using drops of standard liquids, one polar and the other one - non polar. In the research, the used pair of such liquids was water and diododomethane. Ten partial measurements were made and after that the value of the wetting drops was averaged for each sample. During the test were performed constant conditions: the air temperature was $23^{\circ} \mathrm{C}$ and the humidity was at $53 \%$ level. These parameters are very important, because can have impact on the arranging drops on the tested surface (for example drop can evaporate partially and affect the results).

The measurements were performed on the sample surface that was previously cleaned with alcohol to avoid the contamination of the surface and the drop size was $2 \mu \mathrm{l}$ (both for water and diodomethane) to minimize the spreading of the drops under the influence of gravitational forces, that can make the wetting angle lower.

Objects of the research were piston ring samples containing in the coating the inclusion of diamond powder into the porous chrome, at the same time creating a diamond derivating coating. For the research on the goniometer were prepared samples marked as PP, T-1, T-2, T-3, T-4 and T-5. 
The sample marked as PP was a comparative sample, without diamond powder in the coating - only galvanic chromium was applied on the surface. The rest mentioned samples marked as T-1, T-2, T-3, T-4 and T-5 contained in the coating the inclusion of diamond powder into the porous chromium in various weight amounts with a granulation of $0.52 \mu \mathrm{m}$, as detailed in the table below (Table 1).

Table 1. The amount of diamond powder for each sample

\begin{tabular}{|c|c|c|c|}
\hline Sample & $\mathrm{C}[\%]$ & $\mathrm{AL}_{2} \mathrm{O}_{3}[\%]$ & $\mathrm{Cr}[\%]$ \\
\hline $\mathrm{T}-1$ & 0.84 & 0.62 & 98.84 \\
\hline $\mathrm{T}-2$ & 0.89 & 0.09 & 99.07 \\
\hline $\mathrm{T}-3$ & 0.54 & 0.09 & 99.42 \\
\hline $\mathrm{T}-4$ & 0.80 & 0.09 & 99.15 \\
\hline $\mathrm{T}-5$ & 0.49 & 0.07 & 99.48 \\
\hline
\end{tabular}

\subsection{Results}

The Table 2 below presents the average contact angle for each sample, calculated on the basis of the results obtained during the measurements on comparative sample and samples coated with a diamond coating using the pair of standard liquids, which were water and diododomethane.

Table 2 Average wetting angle for samples

\begin{tabular}{|c|c|c|}
\hline & $\begin{array}{c}\text { Average wetting angle for } \\
\text { water }\end{array}$ & $\begin{array}{c}\text { Average wetting angle } \\
\text { for diodomethane }\end{array}$ \\
\hline Sample & {$\left[{ }^{\circ}\right]$} & {$\left[{ }^{\circ}\right]$} \\
\hline PP & 75.7 & 49.1 \\
\hline T-1 & 75.9 & 46.3 \\
\hline T-2 & 77.2 & 46.0 \\
\hline T-3 & 73.6 & 46.2 \\
\hline T-4 & 74.0 & 46.3 \\
\hline T-5 & 70.7 & 36.4 \\
\hline
\end{tabular}

To calculate the surface free energy $\left(\gamma_{S}\right)$ was used the Owens-Wendt method:

$$
\begin{gathered}
\gamma_{\mathrm{S}}=\gamma_{\mathrm{S}}^{\mathrm{d}}+\gamma_{\mathrm{S}}^{\mathrm{p}} \\
\gamma_{\mathrm{SL}}=\gamma_{\mathrm{S}}+\gamma_{\mathrm{L}}-2\left(\gamma_{\mathrm{S}}^{\mathrm{d}} \gamma_{\mathrm{L}}^{\mathrm{d}}\right)^{\frac{1}{2}}-2\left(\gamma_{\mathrm{S}}^{\mathrm{p}} \gamma_{\mathrm{L}}^{\mathrm{p}}\right)^{\frac{1}{2}}
\end{gathered}
$$

where: the index ' $d$ ' indicates the dispersive component of the free surface energy, respectively solid material $(\mathrm{S})$ or liquid (L), and the index ' $\mathrm{p}$ ' indicates the polar component of the free surface energy, respectively solid material (S) or liquid (L).

In addition, it is known that:

$$
\gamma_{\mathrm{L}}(1+\cos \Theta)=2\left[\left(\gamma_{\mathrm{S}}^{\mathrm{d}} \gamma_{\mathrm{L}}^{\mathrm{d}}\right)^{\frac{1}{2}}+\left(\gamma_{\mathrm{S}}^{\mathrm{p}} \gamma_{\mathrm{L}}^{\mathrm{p}}\right)^{\frac{1}{2}}\right]
$$

And after transformation the following formula can be obtained:

$$
\gamma_{\mathrm{L}} \frac{(1+\cos \Theta)}{2}=\left(\gamma_{\mathrm{S}}^{\mathrm{d}} \gamma_{\mathrm{L}}^{\mathrm{d}}\right)^{\frac{1}{2}}+\left(\gamma_{\mathrm{S}}^{\mathrm{p}} \gamma_{\mathrm{L}}^{\mathrm{p}}\right)^{\frac{1}{2}}
$$

To be able to define the value $\gamma_{S}$ of the above equation, the measurements of wetting angles $(\Theta)$ for two different liquids $\gamma_{\mathrm{L}}^{\mathrm{d}}$ and $\gamma_{\mathrm{L}}^{\mathrm{p}}$ were made and the system of two equations was solved (5). Water has the following known values of surface free energy and its components: $\gamma_{\mathrm{L}}=72.8 \mathrm{~mJ} / \mathrm{m}^{2}, \gamma_{\mathrm{L}}^{\mathrm{d}}$ $=21.8 \mathrm{~mJ} / \mathrm{m}^{2}$ and $\gamma_{\mathrm{L}}^{\mathrm{p}}=51 \mathrm{~mJ} / \mathrm{m}^{2}$, while diodomethan is characterized by the following values: $\gamma_{\mathrm{L}}=50.8 \mathrm{~mJ} / \mathrm{m}^{2}, \gamma_{\mathrm{L}}^{\mathrm{d}}$ $=48.5 \mathrm{~mJ} / \mathrm{m}^{2}$ and $\gamma_{\mathrm{L}}^{\mathrm{p}}=2.3 \mathrm{~mJ} / \mathrm{m}^{2}$.

Basing on the Żenkiewicz book [4], after the transformation, the basis for determining the free surface energy value is the system of two equations:

$$
\left\{\begin{array}{l}
\left(\gamma_{\mathrm{S}}^{\mathrm{d}}\right)^{\frac{1}{2}}+1.53\left(\gamma_{\mathrm{S}}^{\mathrm{p}}\right)^{\frac{1}{2}}=7.80\left(1+\cos \theta_{1}\right) \\
\left(\gamma_{\mathrm{S}}^{\mathrm{d}}\right)^{\frac{1}{2}}+0.22\left(\gamma_{\mathrm{S}}^{\mathrm{p}}\right)^{\frac{1}{2}}=3.65\left(1+\cos \theta_{2}\right)
\end{array}\right.
$$

where: $\theta_{1}$ - water wetting drop angle, and $\theta_{2}$ - diodomethan wetting drop angle.

After the calculations, were obtained the following values of dispersion and polar components of free surface energy that are presented in the following table.

Table 3. The value of free surface energy and its components

\begin{tabular}{|c|c|c|c|}
\hline Sample & $\gamma_{\mathrm{s}}^{\mathrm{p}}\left[\mathrm{mJ} / \mathrm{m}^{2}\right]$ & $\gamma_{\mathrm{s}}^{\mathrm{d}}\left[\mathrm{mJ} / \mathrm{m}^{2}\right]$ & $\gamma_{\mathrm{S}}\left[\mathrm{mJ} / \mathrm{m}^{2}\right]$ \\
\hline PP & 7.92 & 29.38 & 37.30 \\
\hline T-1 & 7.25 & 31.13 & 38.38 \\
\hline T-2 & 6.51 & 31.63 & 38.14 \\
\hline T-3 & 8.53 & 30.62 & 39.15 \\
\hline T-4 & 8.32 & 30.66 & 38.98 \\
\hline T-5 & 8.37 & 35.42 & 43.79 \\
\hline
\end{tabular}

where: $\gamma_{\mathrm{S}}-$ free surface energy $\left[\mathrm{mJ} / \mathrm{m}^{2}\right], \gamma_{\mathrm{s}}^{\mathrm{d}}-$ disperse component of free surface energy, $\left[\mathrm{mJ} / \mathrm{m}^{2}\right]$ and $\gamma_{s}^{\mathrm{p}}-$ polar component of free surface energy, $\left[\mathrm{mJ} / \mathrm{m}^{2}\right]$.

The figure below (Fig. 1) presents the chart with the components of surface free energy for each sample.

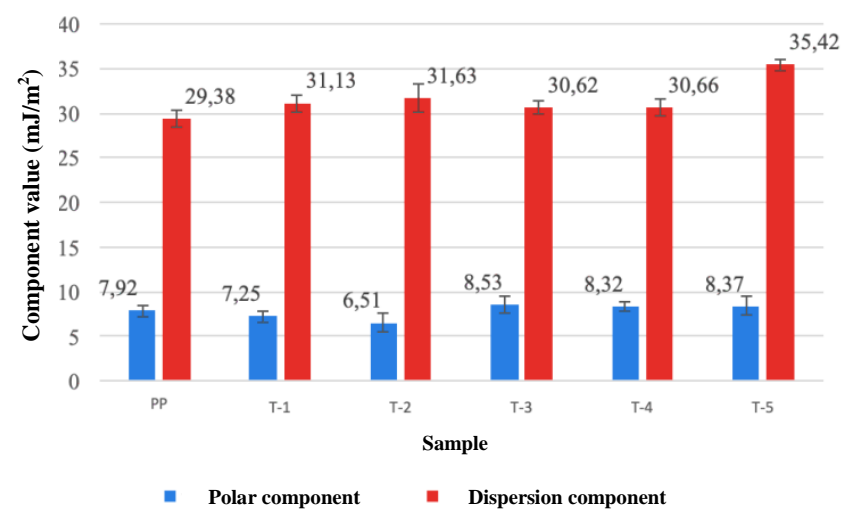

Fig. 1. Free surface energy components values for samples

The measurement results indicate high values of the dispersive component which is the derivative of dispersion interactions between molecules. At the same time, the very small value of the polar component is maintained, that tells about the uneven distribution of atoms, hence its value should be as low as possible because it affects the phenomenon of wetting and formation of the hydration layer on the surface of a solid. The total value of the surface free energy is also not large. An example to compare, for nitrided steel X90CRMOV18, which is an example of material presenting good tribological properties, the sum of dispersion components $\left(33.01 \mathrm{~mJ} / \mathrm{m}^{2}\right)$ and polar $\left(5.45 \mathrm{~mJ} / \mathrm{m}^{2}\right)$ gives the value of free surface energy about $38.46 \mathrm{~mJ} / \mathrm{m}^{2}$, so can be assumed that the values are similar and could indicate 
good properties of a diamond derivating coating. From the presented results in the Table 3 , the sample T-2 was recognized as potentially the best sample from tribological perspective due to the smallest polar component and at the same time the value of the dispersion component is relatively slightly different from the others.

\subsection{Comparative research}

The results obtained within the goniometer research and the influence of free surface energy, as well as its components, on tribological properties of the piston ring sample representing element of friction pair was checked on the tribotester due to using it is possible to determine the wear characteristics of material. The tested elements on the tribotester device were a sample (roll) performing a rotary motion and a counter - sample (block) that was stationary, giving $100 \mathrm{~mm}^{2}$ of contact surface. The samples had the same composition of coating and were named in the same way: PP, T-1, T-2, T-3, T-4 and T-5. The friction path assigned to each sample was about 50000 meters.

Tests on the tribotester were carried out on a continuous, close to the maximum load of the assembly that does not occur in reality. Due to the fact that the basic significance during research on the tribotester is attributed to the loads of the tested friction pairs, including unit pressure and linear speed, the linear speed was determined for $1.25 \mathrm{~m} / \mathrm{s}$ (equal to approx. $350 \mathrm{rpm}$ ) and a load was set to $5 \mathrm{MPa}$. Thus adopted the low velocity and fairly high load values generate extremely difficult conditions in which friction pairs can cooperate and resemble those appearing in the internal combustion engine in the vicinity of $\mathrm{ZZ}$ of the first piston ring, at the beginning of the expansion stroke.

Table 4. Average values obtained after tribotester test

\begin{tabular}{|c|c|c|c|}
\hline Sample & $\begin{array}{c}\text { Average } \\
\text { wearing value } \\
{[\mu \mathrm{m}]}\end{array}$ & $\begin{array}{c}\text { Average friction } \\
\text { coefficient } \\
\text { value }[-]\end{array}$ & $\begin{array}{c}\text { Average } \\
\text { friction } \\
\text { force }[\mathrm{N}]\end{array}$ \\
\hline $\mathrm{PP}$ & 39 & 0.022 & 11 \\
\hline $\mathrm{T}-1$ & 17 & 0.017 & 9 \\
\hline $\mathrm{T}-2$ & 16 & 0.014 & 7 \\
\hline $\mathrm{T}-3$ & 20 & 0.015 & 8 \\
\hline $\mathrm{T}-4$ & 23 & 0.015 & 8 \\
\hline $\mathrm{T}-5$ & 21 & 0.031 & 16 \\
\hline
\end{tabular}

The different friction coefficients and wearing values obtained during tests on the tribotester for each sample confirm the differences in the value of free surface energy and its dispersion and polar components. Differences in surface free energy values for each sample also caused differences in the friction coefficient and wearing values of the tested material combinations. The following figures (Fig. 2 and Fig. 3) show average values of the wearing and values of free surface energy depending on the $\%$ content of $\mathrm{C}$ in the composition of the tested samples.

The diagram (Fig. 2) presents how the value of average sample wearing changed. The research shows that the T-2 sample was characterized by the smallest mean total consumption $(16 \mu \mathrm{m})$, the lowest average friction force $(7 \mathrm{~N})$ and the lowest coefficient of friction (0.014) after $50,000 \mathrm{~m}$ of the friction path.
60

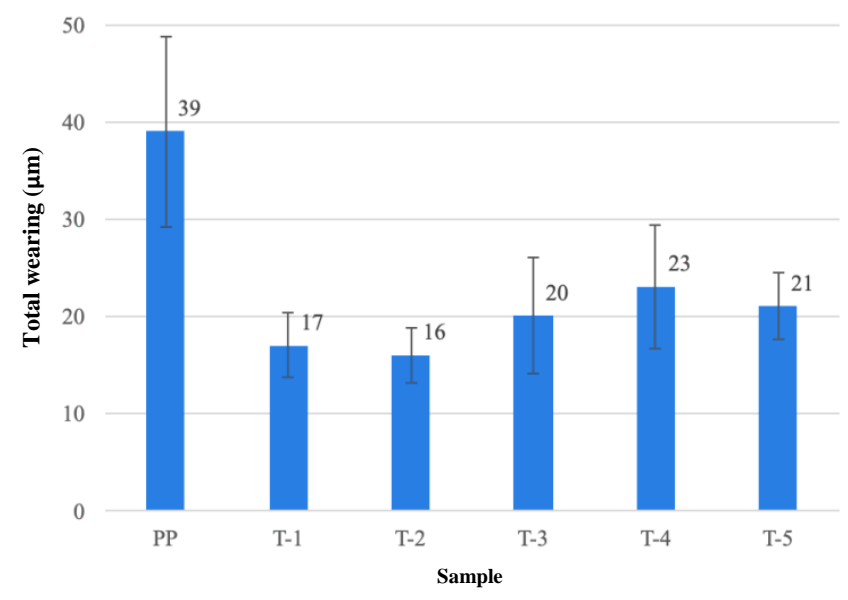

Fig. 2. Total wear of samples

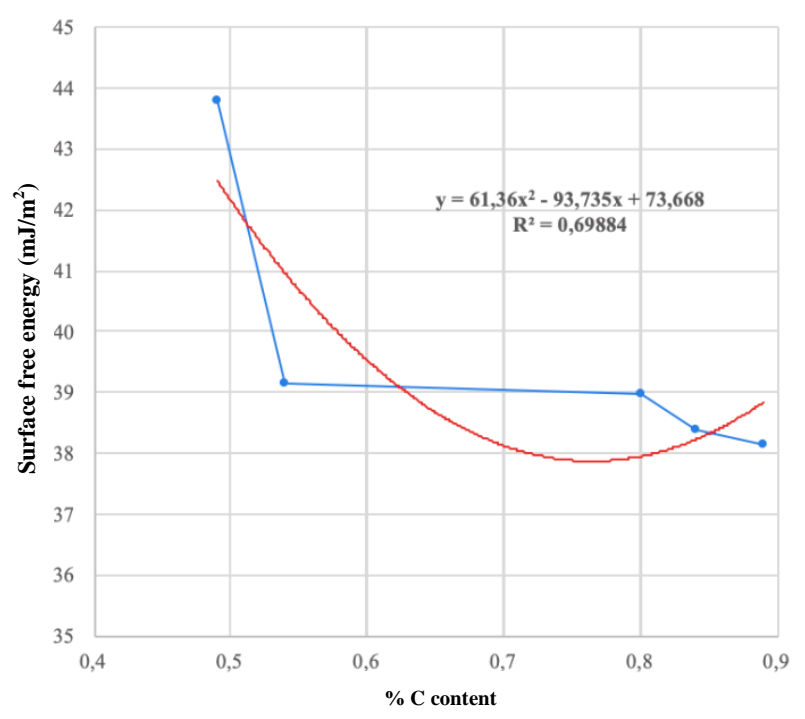

Fig. 3. Relation of free surface energy on the percentage content of $\mathrm{C}$

The diagram above (Fig. 3) shows how the value of free surface energy changes with the change of the $\% \mathrm{C}$ content in the coating composition. This relationship is roughly linear and shows that as the content of the diamond embankment increases, the value of this energy decreases.

\section{Conclusion}

The surface free energy determined for the samples was at a similar level to that mentioned for steel X90CRMOV18, known in terms of tribological properties and successfully used in industry [2]. This could indicate justified attempts to undertake a new parameter, which is surface free energy and its polar components during the selection of materials for elements of friction pairs, the more so because it assumed characteristic values depending on the material composition of coating.

The energetic state of the surface was determined by the measured value of the wetting angle using standard liquids in the measurements and on this basis it was possible to calculate free surface energy and its components dispersion and polar that allow getting information on interfacial interactions and surface wettability, which in the 
other hand shows impact on wearing and tribological properties.

It is observed that the differences in values of the wetting angle, describing the wettability of coatings by model liquids, are reflected in the total free surface energy. Together with the increase in the content of $\% \mathrm{C}$ in the composition of the diamond coating, polar interactions decrease.

Calculation of the free surface energy value and its dispersive and polar components have been carried out using piston ring samples of the internal combustion engine. It has shown that can affect the selection of material for friction elements. These considerations were verified during wear test performed on the tribotester.

It was also observed that the average cumulative wearing determined for a PP sample that did not have a diamond coating was the largest and was $39 \mu \mathrm{m}$. For the sample that had a diamond coating with the highest $\%$ content of $\mathrm{C}$ in the composition $(0.89 \%)$, the wearing was the smallest, only $16 \mu \mathrm{m}$. Judging by the average values of the friction coefficient and values of tangential force, the T-2 sample was the best one from tribological point of view. At the same time, it had the smallest value of the polar component.

The obtained results show that on the basis of the surface free energy values and its components, it is possible to select the material. As a result of the research work carried out on piston ring samples, the best results were obtained for the sample designated as T-2, including the smallest value of the polar component corresponding to the smallest wear of this sample.

The obtained results on the goniometer and tribotester indicate that it is possible to shape the surface wear of diamond - derivating coatings with the determination of free surface energy and its components.

Additionally diamond - derivative coatings are mainly characterized by a lower friction coefficient and a much greater resistance to wear in comparison to rings that are covered by the common super hard coatings. Without a doubt, the application of such coatings will have an impact not only to extend the life of system piston - ring - cylinder, but also will reduce fuel consumption even under the most strenuous conditions of work of the unit.

Solutions to the given research problem is based on the results of the goniometer test. It allows acquiring new knowledge regarding diamond coatings with a specific weight percentage composition. Positive results realized in researches pose a real chance to increase the quantities of produced rings with diamond coating, for example: sport cars, often working in high parameters.

\section{Bibliography}

[1] JAŃCZUK, B., ZDZIENNICKA, A., WÓJCIK, W. Wyznaczanie swobodnej energii powierzchniowej ciał stałych z kąta zwilżania. Wiadomości Chemiczne. 1995, 49, 7-8, 429347.

[2] KAŹMIERCZAK, A. Wpływ stanu energetycznego warstwy wierzchniej elementów silnika spalinowego na zużycie i tarcie par trących. Oficyna Wydawnicza Politechniki Wrocławskiej. Wrocław 2013.

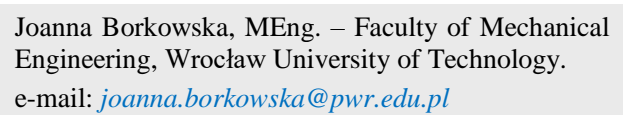

[3] MADEJ, M. Właściwości systemów tribologicznych z powłokami diamentopochodnymi. Wydawnictwo Politechniki Świętokrzyskiej. Kielce 2013.

[4] ŻENKIEWICZ, M. Adhezja i modyfikowanie warstwy wierzchniej tworzy wielkocząsteczkowych. WNT. Warszawa 2000.
Prof. Andrzej Kaźmierczak, DSc., DEng. - Faculty of Mechanical Engineering, Wrocław University of Technology.

e-mail: andrzej.kazmierczak@pwr.edu.pl 